\title{
The Photobiomodulation Effect of 940nm Laser Irradiation on Enterococcus faecalis in Human Root Dentin Slices of Varying Thicknesses
}

\author{
Bryan Martin Sher $^{\circledR}$, Riaan Mulder ${ }^{2 *}$, Norbert Gutknecht ${ }^{1,3}($ \\ 1'Department of Conservative Dentistry, Periodontology and Preventive Dentistry, RWTH University Hospital \\ Aachen, Aachen, Germany \\ 2Department of Restorative Dentistry, University of the Western Cape, Cape Town, South Africa \\ ${ }^{3}$ UNAM University of Namibia, Faculty of Health Sciences, School of Dentistry, Windhoek, Namibia
}

\section{*Correspondence to \\ Riaan Mulder, \\ Department of Restorative Dentistry, University of the Western Cape, Cape Town, South Africa. \\ Tel:+27219373000; \\ Email:rmulder@uwc.ac.za}

Received: September 8, 2020 Accepted: March 3, 202 Published online August 30, 2021

\section{Introduction}

The main etiological factor of pulpal and periapical infections is the invasion of bacteria into the pulpal and endodontic systems. ${ }^{1}$ Successful treatment of these infections would require the removal and/or destruction of these microorganisms and create an effective coronal and apical seal to prohibit the reinfection of bacteria and influx of nutrients into the endodontic system. The ability of bacteria to penetrate deep into the dentin tubules and to form biofilms as well as the adhesion of certain bacteria to the dentin walls makes the destruction and removal of bacteria from the three-dimensional dentinal network a challenging task. ${ }^{2,3}$ Due to the complexity of this network, about $30 \%-45 \%$ of the root canal system escapes chemo-mechanical instrumentation ${ }^{4}$ as per the normal endodontic procedure with the dentist. Lasers have been used as an additional step to kill bacteria that could not be reached by chemo-mechanical instrumentation. Studies show that in favourable conditions, bacteria can penetrate to a depth of more than $1000 \mu \mathrm{m}$ into the dentinal tubules. ${ }^{2}$

Numerous previous studies have been conducted to evaluate the bactericidal effect of various wavelengths of lasers, but most of these studies were conducted on dentine slices of 100, 300, 500, and $1000 \mu \mathrm{m} .^{5-7}$ They were conducted with dentine samples up to $1000 \mu \mathrm{m}$, therefore limiting our understanding as to the effects of lasers and biocides, with one study beyond $2000 \mu \mathrm{m} .{ }^{8}$ This in vitro study aimed to compare the photobiomodulation effect of a $940 \mathrm{~nm}$ laser on Enterococcus faecalis through varying thicknesses of human root dentin slices.

Please cite this article as follows: Sher BM, Mulder R, Gutknecht N. The Photobiomodulation Effect of 940nm Laser Irradiation on Enterococcus faecalis in Human Root Dentin Slices of Varying Thicknesses. J Lasers Med Sci. 2021;12:e48. doi:10.34172/jlms.2021.48 


\section{Materials and Methods \\ Sample Preparation}

Thirty-five caries-free human first pre-molar teeth were removed for orthodontic purposes and cleaned with a curette. The teeth were individually stored in $5 \mathrm{~mL}$ microcentrifuge tubes (Eppendorf Vertrieb, WesselingBerzdorf, Germany) containing $1 \%$ thymol of a sterile physiological solution at a temperature of $4^{\circ} \mathrm{C}$ until further use. With the aid of a slow-speed saw (Steurs Minitom, Copenhagen, Denmark) and a cooled $80 \times 0.2$ $\mathrm{mm}$ diamond blade (Horico, Berlin, Germany), the teeth were first sectioned at the cemento-enamel junction. The roots were subsequently sectioned parallel to the root canal lumen at various thicknesses $(500,1000,1500,2000$, 2500 , and $3000 \mu \mathrm{m})$. The thickness of the dentin slices after surface roughness standardization was confirmed with a microcaliper, and slices below the tolerance of \pm 5 $\mu \mathrm{m}$ were excluded from the study.

The size of the dentine slices was standardized to the resulting total number of thirty-five precise slices with a dimension of $10 \times 3 \mathrm{~mm} \times$ specified thickness in $\mu \mathrm{m}$ and surface roughness of $0.4 \mu \mathrm{m}$. Root dentin slices with thicknesses of 500, 1000, 1500, 2000, 2500, and $3000 \mu \mathrm{m}$ $(\mathrm{n}=5$ each) were randomly divided into 6 experimental groups to be leased. The second group of $2000 \mu \mathrm{m}$ served as the positive control with no laser exposure. Enumeration and subsequent $E$. faecalis recovery from separate dentine slices were confirmed with an additional fifteen dentine slices with a thickness of $2000 \mu \mathrm{m}$ each. These additional 15 dentine slices were inoculated with $2 \mu \mathrm{L}$ of the prepared McFarland standard 0.5 inoculum after its preparation described below, to determine the pathogen recovery at each step of the methodology. The additional fifteen dentine slices used for enumeration and recovery assessed the colony-forming units present at various time intervals. The samples were distributed to: five dentine slices immediately after the inoculation of the dentin slice at the start of the 1-hour incubation period $\left(\mathrm{n}=5\right.$; pathogen recovery: $\left.418.2 \pm 60 \mathrm{CFU} \times 10^{4} / \mathrm{mL}\right)$; five after 1 -hour incubation at $37^{\circ} \mathrm{C}(\mathrm{n}=5$; pathogen recovery: $416.9 \pm 55 \mathrm{CFU} \times 10^{4} / \mathrm{mL}$ ) and five after the last dentin slice was lased ( $n=5$; pathogen recovery: $410.6 \pm 48 \mathrm{CFU}$ $\mathrm{x} 10^{4} / \mathrm{mL}$ ).

\section{Sample Surface Roughness}

The surface roughness $(\mathrm{Ra})$ of the dentine slices required standardization to allow the E. faecalis to have the same opportunity to adhere to the dentin surface. The dentine was polished with wet 2500 grit carbide paper until the surface roughness meter recorded a Ra value of $0.4 \mu \mathrm{m}$.

The $\mathrm{Ra}$ of the dentin slices was measured with a Leeb surface roughness tester and a standard sensor (Model Leeb432, Chongqing Leeb Instruments Co Ltd, China). The $\mathrm{Ra}$ meter had a measuring range for $\mathrm{Ra}$ between 0.005-16 $\mu \mathrm{m}$. The testing parameters were: surface roughness $(\mathrm{Ra})$, Filter set at Gauss, and the assessment length $(\lambda c)$ at $0.8 \mathrm{~mm} \times n 5$ (assessment length ( $\mathrm{Ln}=\mathrm{lr}$ $\mathrm{x} n$ ); $\mathrm{Ln}=3.2 \mathrm{~mm}$ ) (International Organization for Standardization. ISO 4288: Rules and Procedures for Assessment of Surface Texture. Geneva: ISO; 1998). The standard stylus had a natural diamond at a $90^{\circ}$ cone angle with a $5 \mu \mathrm{m}$ tip radius. The stylus applied a force to the sample of $<4 \mathrm{mN}$. The travel speed (Vt) for the above parameters was $0.135 \mathrm{~mm} / \mathrm{s}$ and the measurement accuracy was $\pm 10 \%$. The Ra was measured by recording the $\mathrm{Ra}$ on both sides of the dentine slice with two parallel measurements by way of the assessment length recorded $1 \mathrm{~mm}$ apart and two lines perpendicular to that $(n=4)$ per sample. The aforementioned measurements $(n=4)$ were therefore recorded per side, and the average of the eight measurements was used as the mean Ra per specimen.

\section{Dentin Surface Cleaning}

Each of the precise slices was cleaned according to the guidelines of the American Association of Endodontists' clinical protocol for the preparation of root canal systems. The slices were immersed in a $17 \%$ EDTA solution for 1 minute to remove the inorganic components of the smear layer. The organic components were removed by irrigation with $6 \%$ sodium hypochlorite $(\mathrm{NaOCl}) .{ }^{9}$ The slices were then individually stored in sterile glass bottles in $1 \mathrm{ml}$ of phosphate-buffered saline and sterilized in an autoclave at $120^{\circ} \mathrm{C}$ for 20 minutes. The sterile dentin slices were transferred to sterile Petri dishes and allowed to dry in a temperature-controlled incubator for 24 hours.

\section{Bacterial Inoculation}

The broth was made by dissolving $25 \mathrm{~g}$ of powder (Luria Broth- EXMix ${ }^{\text {Tx }}$ powder microbial growth medium) in 1 Litre of de-ionized water and sterilized by an autoclave at $121^{\circ} \mathrm{C}$ for 20 minutes. E. faecalis (ATCC 29212) bacteria were reconstituted in Lysogeny Broth (Luria Broth) for 24 hours at $37^{\circ} \mathrm{C}$ and streaked on a standard agar contact plate (TSA LTHth-ICR, Merck Life Science GmbH; Eppelheim; Germany; Batch 140477). A single colony was used to prepare a McFarland standard of 0.5 in phosphate-buffered saline (ICN Biomedicals Inc., Ohio, USA). The McFarland standard of 0.5 was standardized with a DensiCheck plus (BioMerieux Inc., Hazelwood, Missouri, USA). The DensiCHECK plus measuring device used a $580 \mathrm{~nm}$ wavelength. The $0.5 \mathrm{McF}$ arland standard was equivalent to a concentration of $1.5 \times 10^{8} \mathrm{E}$. faecalis cells $/ \mathrm{mL}$ in the phosphate-buffered saline solution. With the use of a calibrated micropipette, the dentin samples were inoculated immediately after McFarland standard production on one side of the dentine slice $(10 \times 3$ $\mathrm{mm}$ ) with $2 \mu \mathrm{L}$ of the prepared $0.5 \mathrm{McF}$ arland standard inoculum and allowed to dry in a sterile closed Petri dish for one hour in a $37^{\circ} \mathrm{C}$ incubator. 


\section{Laser Irradiation}

The samples were randomly divided into seven groups: six groups with five samples each according to the thickness of the slice and the positive control group consisting of five samples of $2000 \mu \mathrm{m}$ dentine slices that were inoculated, but not laser-irradiated. The dentine slices requiring laser irradiation was rotated $180^{\circ}$ clockwise, thus performing laser radiation on the opposite side to where E. faecalis was inoculated. The laser specifications are presented in Table 1. The $940 \mathrm{~nm}$ laser (Biolase, San Clemente, CA, USA) with a non-initiated $200 \mu \mathrm{m}$ bare end fibre at the power of 1 Watt in a continuous wave setting served as the delivery system.

The clinical laser irradiation activation cycle is usually advised at 10 seconds for a $20 \mathrm{~mm}$ root length at a coronal withdrawal speed of $2 \mathrm{~mm} / \mathrm{s}$. Based on half of the lumen surface area used in this study, it was appropriate to divide the laser irradiation activation cycle time into 5 seconds. The dentine slice used $(10 \times 3 \mathrm{~mm})$ had a 2 -dimensional surface area of half the lumen surface area (i.e. $30 \mathrm{~mm}^{2}$ ) compared to the average 3-dimensional lumen surface area of mandibular premolars (i.e. $58.51 \pm 16.41 \mathrm{~mm}^{2}$ ). ${ }^{10}$ The laser irradiation activation cycle for this study was therefore repeated a total of four times with a side-toside movement at a "withdrawal" speed of $2 \mathrm{~mm} / \mathrm{s}$ with the optical fiber tip held at a $5^{\circ}$ angle to the dentine slice. The total laser irradiation activation cycle time of 5 seconds per application to the dentine slice would take into account the clinical helical nature of irradiating root canals. Additionally, the temperature transfer to the outer surface of the dentine slice posed no risk of thermal insult to the viability of periodontal structures as established in the literature. ${ }^{11}$ The $200 \mu \mathrm{m}$ tip was replaced after the

Table 1. Laser Parameters

\begin{tabular}{ll}
\hline & Laser Parameter \\
\hline Type of laser & $940 \mathrm{~nm}$ nGaAsP Semi-conductor diode \\
Laser company & Biolase, San Clemente, CA, USA \\
Emission mode & Continuous Wave \\
Delivery system & Optical fibre \\
Power & $1 \mathrm{~W}$ \\
& $\begin{array}{l}5 \text {-second laser irradiation by the } \\
\text { operator } / 5 \text {-second laser off to allow } \\
\text { dentine to cool (procedure repeated } \\
\text { four times) }\end{array}$ \\
Time on/Time off & $200 \mu \mathrm{m}$ \\
\hline Spot diameter at the tip & $0.0003 \mathrm{~cm}^{2}$ \\
Spot area at the tip & $3183 \mathrm{~W} / \mathrm{cm}^{2}$ \\
Power density at the tip & 20 Joules $(5 \mathrm{~J}$ per laser irradiation of 5 \\
seconds; repeated four times)
\end{tabular}

laser irradiation of each group. A single-blinded operator was used to ensure conformity of the laser irradiation following local statutory regulations for laser safety. ${ }^{12}$

\section{Bacteriological Analysis}

To simulate physiological conditions, all the irradiated dentin slices were stored in individual $2 \mathrm{~mL}$ Cryotubes containing $1.8 \mathrm{~mL}$ of sterile Lysogeny Broth and incubated at a temperature of $37^{\circ} \mathrm{C}$ for 24 hours. The storage of the irradiated dentin specimens incubated in the Lysogeny Broth provided nutrition to the E. faecalis bacteria. After 24 hours, the bacteria were separated from the dentine slices using a 10-second vortex. The vortexed Lysogeny Broth containing a $1 \mathrm{~mL}$ suspension of $E$. faecalis underwent serial dilutions in a sterile phosphatebuffered saline solution of $\log 10^{3}$. Streaks of $10 \mu \mathrm{L}$ from the serial diluted $E$. faecalis were completed on the agar plates followed by 24 -hour incubation at $37^{\circ} \mathrm{C}$ in a $10 \%$ $\mathrm{CO}_{2}$ atmosphere.

Upon the completion of the incubation period, the colony-forming units of $E$. faecalis were counted with a colony counting system. The statistical analysis was completed with a one-way ANOVA with a Bonferroni and Holm post-hoc test at a significance level of $P>0.05$. The post-hoc tests would likely identify which of the pairs of treatments are significantly different from each other (Statistical analysis with R Core Team (2013); (R: A language and environment for statistical computing. $\mathrm{R}$ Foundation for Statistical Computing, Vienna, Austria).

\section{Results}

The colony-forming units of E. faecalis revealed the data presented in Table 2. The Bonferroni and Holm interference showed significant differences $(P<0.01)$ between the bactericidal effects for dentine slices of 500 , 1000 , and $1500 \mu \mathrm{m}$. There was a significant reduction in the E. faecalis growth with the positive control of $2000 \mu \mathrm{m}$ thickness that did not receive any laser treatment. The lased dentine slices of $2000,2500 \mu \mathrm{m}$ did not present with a significant lower bacterial growth $(P>0.05)$, compared to the positive control dentine slices. The lased slices of $2000 \mu \mathrm{m}$ had fewer bacteria than the positive control without the laser, but $2500 \mu \mathrm{m}$ had a non-significantly greater amount of colony-forming units. When the 3000 $\mu \mathrm{m}$ slice treated with the laser and E. faecalis colonyforming units were considered, the bacterial growth through photobiomodulation was significantly $(P<0.01)$ more than the positive control tooth that received no laser treatment.

\section{Discussion}

Enterococcus faecalis has been identified as the microorganism that is present at root canal failure. ${ }^{1}$ Strains isolated from the oral biofilm or saliva revealed high percentages of virulent genes and resistance to antibiotics 
Table 2. Average Colony Forming Units (CFUs) of Enterococcus faecalis on Different Thicknesses Of Dentine

\begin{tabular}{lcc}
\hline Slice thickness in Group & CFU $\times \mathbf{1 0}^{-4} \mathbf{m L}$ & \pm SD CFU $\times \mathbf{1 0}^{-4} \mathbf{m L}$ \\
\hline No laser positive control $2000 \mu \mathrm{m}$ & 411.6 & \pm 25.16 \\
$500 \mu \mathrm{m}$ & $195^{*}$ & \pm 24.75 \\
$1000 \mu \mathrm{m}$ & $262.8^{*}$ & \pm 21.75 \\
$1500 \mu \mathrm{m}$ & $330.6^{*}$ & \pm 27.03 \\
$2000 \mu \mathrm{m}$ & 384.4 & \pm 30.59 \\
$2500 \mu \mathrm{m}$ & 442.6 & \pm 27.10 \\
$3000 \mu \mathrm{m}$ & $556.8^{*}$ & \pm 34.21 \\
\hline
\end{tabular}

*Indicates significant difference from the positive control group.

similar to isolates obtained from systemic infections. ${ }^{13}$ This is a reason why it has been well established that lasers are bactericidal on E. faecalis up to $1000 \mu \mathrm{m}$ in dentinal tubules. ${ }^{14}$

It had been concluded that the $980 \mathrm{~nm}$ laser had a lower penetration depth (based on E. faecalis reduction) than the $940 \mathrm{~nm}$ laser. The $980 \mathrm{~nm}$ laser at $2.8 \mathrm{~W}$ in continuous wave provide a $32 \%$ reduction in E. faecalis on $500 \mu \mathrm{m}$ bovine dentine slices. ${ }^{15}$ The results of this study indicated that there was a photobiomodulation effect on the bacteria, with growth stimulation in thicker dentine slices $(2500-3000 \mu \mathrm{m})$. The results of this in vitro study for dentine slices of $500 \mu \mathrm{m}$ revealed a $53 \%$ reduction of E. faecalis colony forming units compared to $2000 \mu \mathrm{m}$ positive control where no laser application was performed. Similarly, the log kill rates of dentine slices exposed to laser irradiation were $36.84 \%(1000 \mu \mathrm{m}), 19.67 \%$ (1500 $\mu \mathrm{m})$, and $6.6 \%(2000 \mu \mathrm{m})$ compared to the positive control. Even though the complete bacterial reduction was not achieved in dentine slices below thicknesses of $2000 \mu \mathrm{m}$, sub-lethal damage to the bacteria inhibited cell growth. ${ }^{16}$ The results of decreasing cell death as the dentine thickness increases are important if the consideration is made to the photobiomodulation (photobiostimulation) effect in thicker dentine that may be present. The clinician should consider the thickness determination of the apical root third from the radiographs. The thickness of the root surface is important not only for E. faecalis but also for the laser irradiation effect on Streptococcus mutans. A study with an $810 \mathrm{~nm}$ diode laser at 7 Watt was found to reduce the efficacy of the kill in the Streptococcus mutans by nearly $50 \%$ as the thickness of the tooth doubled. ${ }^{8}$ It was noted that as the dentine slices became thicker, the $\log$ kill rate was reduced. The $2000 \mu \mathrm{m}$ positive control dentine slices simulated the growth of E. faecalis when no laser irradiation was present. This positive growth determined in the $2500 \mu \mathrm{m}$ dentine slices of $+7.53 \%$ and $+35.27 \%$ for the $3000 \mu \mathrm{m}$ dentine slices was attributed to the photobiomodulation growth effect on the E. faecalis.

\section{Conclusion}

Laser irradiation treatment significantly reduced $E$. faecalis growth through thicknesses of 500, 1000, and $1500 \mu \mathrm{m}$. Once the tooth thickness achieved 2000 and $2500 \mu \mathrm{m}$, the bacterial growth was not significantly more $(2500 \mu \mathrm{m})$ or less $(2000 \mu \mathrm{m})$ than the positive control slices that received no laser. Once the tooth thickness of $3000 \mu \mathrm{m}$ was lased, the E. faecalis growth was stimulated significantly by the laser compared to the E. faecalis growth of the positive control. This trend is seen for an increase in bacterial growth in Table 2 for dentine slices from 2500 and $3000 \mu \mathrm{m}$. Future studies would need to investigate and compare results to determine the ideal laser irradiation to achieve significant pathogen reduction and prevent photobiomodulation (photobiostimulation) compared to the thickness of the tooth structure without a thermal insult on the periodontal complex.

\section{Limitations of the study}

Like other studies, this study design did not measure the power of the laser through the dentine slices (with a thermopiledetector) nor the energy penetrating through the slices (with a photodiode detector or a pyroelectric detector).This is an area of study that could advance the understanding of the anti-bacterial effect through various dentine slice thicknesses.

\section{Ethical Considerations}

Ethical approval was obtained from the research ethics committee of The University of Western Cape (Ethical approval: BM19/7/5).

\section{Conflict of Interests}

The authors declare no conflict of interest.

\section{Acknowledgments}

The results formed part of a postgraduate program for Dr BM Sher. Gutknecht was the project supervisor for degree purposes and edited the article. Sher and Mulder wrote the article and conducted the experiments. Mulder provided technical, blinding and microbiological assistance. Financial and material support was provided by Mulder.

\section{References}

1. Haapasalo $M, \emptyset$ rstavik D. In vitro Infection and Disinfection of Dentinal Tubules. J Dent Res. 1987;66(8):1375-1379. doi :10.1177/00220345870660081801.

2. Vatkar NA, Hegde V, Sathe S. Vitality of Enterococcus faecalis inside dentinal tubules after five root canal disinfection methods. J Conserv Dent. 2016;19(5):445-449. doi:10.4103/0972-0707.190019.

3. George S, Kishen A, Song KP. The role of environmental changes on monospecies biofilm formation on root canal wall by Enterococcus faecalis. J Endod. 2005;31(12):867872. doi:10.1097/01.don.0000164855.98346.fc.

4. Siqueira JF, Rôças IN, Alves FRF, Santos KRN. Selected endodontic pathogens in the apical third of infected root canals: A molecular investigation. J Endod. 2004;30(9):638643. doi:10.1097/01.don.0000125875.88377.85.

5. Klinke T, Klimm W, Gutknecht N. Antibacterial effects of Nd:YAG laser irradiation within root canal dentin. J Clin Laser Med Surg. 1997;15(1):29-31. doi:10.1089/ 
clm.1997.15.29.

6. Schoop U, Kluger W, Moritz A, Nedjelik N, Georgopoulos A, Sperr W. Bactericidal effect of different laser systems in the deep layers of dentin. Lasers Surg Med. 2004;35(2):111116. doi:10.1002/lsm.20026.

7. Gutknecht N, Hassan N Al, Martins RM, Conrads G, Franzen R. Bactericidal effect of 445-nm blue diode laser in the root canal dentin on Enterococcus faecalis of human teeth. Lasers Dent Sci. 2018;2:247-254. doi:10.1186/s12903018-0611-6.

8. Lee BS, Lin YW, Chia JS, et al. Bactericidal effects of diode laser on Streptococcus mutans after irradiation through different thickness of dentin. Lasers Surg Med. 2006;38(1):62-69. doi:10.1002/lsm.20279.

9. Americam Association of Endodontists. Guide to Clinical Endodontics. $6^{\text {th }}$ Edition. Chicago; 2016. https://www. aae.org/specialty/clinical-resources/guide-clinicalendodontics/

10. Boschetti E, Silva-Sousa YTC, Mazzi-Chaves JF, Leoni GB, Versiani MA, Pécora JD, Saquy PC, Sousa-Neto MD. Micro-CT Evaluation of Root and Canal Morphology of Mandibular First Premolars with Radicular Grooves. Braz Dent J. 2017;28(5):597-603. doi:10.1590/01036440201601784
11. Hmud R, Kahler WA, Walsh LJ. Temperature changes accompanying near infrared diode laser endodontic treatment of wet canals. J Endod. 2010;36(5):908-911. doi: 10.1016/j.joen.2010.01.007.

12. Naidoo S, Mulder R. The use of laser-based technologies in dentistry: Ethical issues and safety considerations. $S$ Afr Dent J. 2015;70(10):464-466.

13. Anderson AC, Jonas D, Huber I, et al. Enterococcus faecalis from food, clinical specimens, and oral sites: Prevalence of virulence factors in association with biofilm formation. Front Microbiol. 2016;6:1534. doi:10.3389/ fmicb.2015.01534.

14. Gutknecht N, Moritz A, Conrads G, Sievert T, Lampert F. Bactericidal effect of the Nd:YAG laser in in vitro root canals. J Clin Laser Med Surg. 1996;14(2):77-80. doi:10.1089/clm.1996.14.77.

15. Gutknecht N, Franzen R, Schippers M, Lampert F. Bactericidal Effect of a 980-nm Diode Laser in the Root Canal Wall Dentin of Bovine Teeth. J Clin Laser Med Surg. 2004;22(1):9-13. doi:10.1089/104454704773660912.

16. Dworkin M. Endogenous photosensitization in a carotinoidless mutant of Rhodopseudomonas speroides. $J$ Gen Physiol. 1958;43:1099-1112. 